\title{
Body Composition is Associated With Bone and Glucose Metabolism in Postmenopausal Women With Type 2 Diabetes Mellitus
}

\author{
I. RAŠKA Jr. ${ }^{1}$, M. RAŠKOVÁ ${ }^{1}$, V. ZIKÁN ${ }^{1}$, J. ŠKRHA $^{1}$ \\ ${ }^{1}$ Third Department of Medicine - Department of Endocrinology and Metabolism, First Faculty of \\ Medicine, Charles University in Prague and General University Hospital in Prague, Czech Republic
}

Received January 29, 2016

Accepted June 8, 2016

On-line October 26, 2016

\section{Summary}

Type 2 diabetes mellitus (T2DM) is associated with increased fracture risk; the underlying mechanism remains unexplained. This study aimed to investigate the relationships between body composition and bone and glucose metabolism in postmenopausal women with T2DM. Dual-energy X-ray absorptiometry was used to measure bone mineral density (BMD) and body composition. A total of 68 postmenopausal women with T2DM and 71 controls were eligible for the study. In contrast to normal BMD in T2DM, a similar prevalence of low-trauma fractures was observed in both groups. T2DM women had significantly higher Trunk fat\% and $A / G$ ratio and significantly lower Legs LM\% and Legs FM\%. Legs LM\% was significantly lower in fractured T2DM group and negatively correlated with glycaemia and HbA1c $(p<0.01)$. Serum osteocalcin was significantly lower in T2DM and inversely correlated with $\mathrm{FM} \%$, Trunk FM\% and $A / G$ ratio $(p<0.01)$ and positively correlated with Legs $\mathrm{FM} \%$ and total LM\% $(\mathrm{p}<0.05)$. In conclusion, abdominal obesity and decrease in muscle mass may contribute to low bone formation in T2DM women. Further research is needed to unravel underlying pathophysiological mechanisms and to determine whether maintenance of muscle mass, especially in the lower extremities and/or reduction of central fat mass can prevent fractures.

\section{Key words}

Bone mineral density $\bullet$ Body composition • Fat mass $\bullet$ Lean mass - Type 2 diabetes mellitus

\section{Corresponding author}

V. Zikán, Third Department of Internal Medicine, First Faculty of Medicine, Charles University in Prague and General University
Hospital in Prague, U Nemocnice 1, 12808 Prague 2, Czech Republic. E-mail: vit.zikan@vfn.cz

\section{Introduction}

Type 2 diabetes mellitus (T2DM) and osteoporosis belongs to the most prevalent metabolic disorders occurring mostly in middle-age and older adults, respectively. Although osteoporosis and T2DM have been viewed as separate diseases, accumulating evidence indicates that similar pathophysiological mechanisms underlie both of them (Starup-Linde and Vestergaard 2015). Nowadays, there is evidence that patients with T2DM have an increased risk of fractures compared with those without diabetes (Yamamoto et al. 2009, Martinez-Laguna et al. 2015). Despite the increased fracture risk, bone mineral density (BMD) is generally higher in patients with T2DM (Yamamoto et al. 2009). The underlying mechanisms of increased fracture risk in T2DM are not fully understood. T2DM is frequently accompanied by changes in body composition, including a decrease in muscle mass and strength, particularly in lower extremities and increase in fat mass (Moseley et al. 2011, Park et al. 2006). The loss of muscle strength and/or muscle mass might contribute to fractures in T2DM patients. In both cross-sectional and longitudinal studies, accelerated loss of muscle mass and strength is recorded in individuals with diabetes, is greater with longer diabetes duration or higher $\mathrm{HbA}_{1 \mathrm{c}}$, and is attenuated by use of insulin sensitizers (Park et al. 2009, Lee et al. 2011, Kalyani et al. 2014). The pathogenesis of diabetes-related muscle loss is 
multifactorial and has been attributed to hyperglycemia, oxidative stress, inflammation, endocrine changes, inactivity, and the accumulation of advanced glycation endproducts (AGEs) (Kalyani et al. 2015, Tanaka et al. 2015).

Several studies have indicated that also fat mass is related to BMD and fracture risk ( $\mathrm{Ng}$ et al. 2013; Caffarelli et al. 2014). Moreover, recent studies in animals suggest that fat-muscle-bone relationships may be related to circulating osteocalcin, an osteocyte and osteoblasts specific peptide (Kanazawa et al. 2015). Osteocalcin knockout mice have increased fat mass and decreased insulin sensitivity (Lee et al. 2014), whereas treatment of wild-type mice with under-carboxylated osteocalcin leads to decreased fat mass and improved insulin sensitivity (Ferron et al. 2014). Several clinical studies (Kindblom et al. 2009, Kanazawa et al. 2011) have shown that serum total or under-carboxylated osteocalcin concentrations were associated with glucose metabolism and fat mass in patients with T2DM or in non-diabetes subjects. These experimental and clinical findings suggest that osteocalcin may play an important role both in bone and glucose-fat metabolism.

Measuring body composition by dual energy X-ray absorptiometry (DXA) has the ability to accurately identify fat mass and fat-free mass (lean mass) and their distribution throughout the body with high precision (Lohman et al. 2009). In the present study, we therefore examined the relationships of BMD and biochemical variables of bone and glucose metabolism with body composition indices as assessed by DXA in postmenopausal women with and without T2DM.

\section{Methods}

\section{Subjects}

Postmenopausal women with T2DM on antidiabetic medication or newly detected T2DM as well as control group of postmenopausal women without T2DM, who attended a preventive bone mineral density (BMD) measurement, were selected prospectively between August 2012 and July 2014. Exclusion criteria were abnormal serum calcium level, serum creatinine level $>110 \mu \mathrm{mol} / \mathrm{l}$, estimated glomerular filtration rate (eGFR) $<1 \mathrm{ml} / \mathrm{s} / 1.73 \mathrm{~m}^{2}$ and proteinuria, diseases other than osteoporosis and T2DM that would interfere with bone metabolism such as diabetic nephropathy, primary hyperparathyroidism, liver disease, malabsorption; or use of any other medication affecting bone metabolism within the 5 years prior the selection, such as bisphosphonates, raloxifene, strontium ranelate, hormone replacement therapy, glucocorticoids, thiazolidinedione or active vitamin D supplements. The information on the risk factors for osteoporosis, namely family history of osteoporosis and a personal history of any kind of bone fracture as an adult (after menopause), physical activity, alcohol intake and smoking were obtained by questionnaires and medical records. Patients with a history of immobility were excluded from the study. A total of 68 postmenopausal women with T2DM (mean age $63 \pm 6.5$ years) were eligible for the analysis. The majority of T2DM patients (53\%) were treated by metformin; $22 \%$ of patients were treated by combination of metformin with gliptins or sulfonylurea derivatives and $3 \%$ of patients were taking sulfonylurea derivatives. Moreover, $22 \%$ of patients had newly detected T2DM without T2DM treatment. The diabetics did not have the chronic complications and no signs of renal complications at the time of examination. There were no significant differences in BMD, body composition or measured biochemical markers between treatment groups or between treated and untreated patients with T2DM. The same exclusion criteria were respected also for the control group. A total of 71 age- and weight-matched postmenopausal control women (mean age $63 \pm 8.8$ years), were eligible for the study. The study was undertaken with the understanding and written consent of each subject, with the approval of the Ethics Committee of the General University Hospital and First Faculty of Medicine, and within compliance of the National Legislation and the Code of Ethical Principles for Medical Research Involving Human Subjects of the World Medical Association (Declaration of Helsinki).

\section{Anthropometric measurement}

Standing height and weight measurements were completed with participants wearing lightweight clothing and no shoes. Height was obtained with a stadiometer. Weight was measured on a calibrated digital scale. Body mass index (BMI) was calculated as weight $(\mathrm{kg})$ divided by height squared $\left(\mathrm{m}^{2}\right)$.

\section{Body composition and bone measures}

Body composition, total body bone mineral content (TBBMC) and bone mineral density (BMD) was measured at the lumbar spine (L1-L4), total femur (TF), femoral neck (FN), distal radius (DR) and whole body (WB) in all participants by using a dual energy X-ray 
absorptiometry (DXA) densitometer (Discovery A, Hologic, Inc, MA, USA, Software version: Apex 3.5.1). Patients and control group were measured on the same densitometer. The short-term precision in vivo errors for the lumbar spine (L1-L4), total femur, and femoral neck were $0.7 \%, 0.9 \%$ and $1.9 \%$, respectively; the long-term precision in vitro error was $0.32 \%$. We measured bodycomposition variables from the whole body scan. The CVs for fat and lean mass by DXA are $1.9 \%$ and $2.6 \%$, respectively, for our site. Taking into account the large variation of body composition parameters, we expressed the body composition variables also as mass percentages. Total and regional body composition variables were calculated as follows:

Fat mass indices: Fat mass index $(F M I)=$ Total body fat mass/height $\left(\mathrm{kg} / \mathrm{m}^{2}\right)$; Percentage of total body fat mass $(F M \%)=$ total body fat mass/whole body mass $\mathrm{x}$ 100; Percentage of trunk fat (Trunk fat \%) = trunk fat mass/total fat mass x 100; Legs fat mass index (Legs $F M I)=($ right leg + left leg fat mass $) /$ height $\left(\mathrm{kg} / \mathrm{m}^{2}\right)$; Percentage of total legs fat mass (Legs FM\%) = (right leg + left leg fat mass)/total fat mass x 100; Trunk/Legs FM ratio $=$ trunk fat mass/legs fat mass; Android to gynoid ratio (A/G ratio) was determined by using fat percentage in $A$ and in the $G$ regions. Android FM was defined as adipose deposition around the abdomen; whereas, gynoid FM was adipose tissue accumulating around the hips. The regions of interest (ROI) were defined using the software provided by the Hologic manufacture.

Lean mass indices: Lean mass index (LMI) = total body lean mass/height $\left(\mathrm{kg} / \mathrm{m}^{2}\right)$; Percentage of total body lean mass $(L M \%)=$ total body lean mass/whole body mass x 100; Legs lean mass index (Legs LMI) = (right leg + left leg lean mass)/height $\left(\mathrm{kg} / \mathrm{m}^{2}\right) ;$ Percentage of total leg lean mass (Legs LM\%) = (right leg + left leg lean mass)/total lean mass x 100.

The data from the third National Health and Nutrition Examination Survey (NHANES III) were used as the reference sample to calculate the T-scores, as recommended by Kanis and Gluer (2000). According to the criterion set by the World Health Organization, a subject was classified as having osteopenia or osteoporosis if BMD was below 1.0 (T-score $<-1.0$ ) or 2.5 standard deviations ( $\mathrm{T}$-score $\leq-2.5$ ) below the young reference population, respectively. Gender-specific reference data were used to calculate the T-scores.

\section{Laboratory analyses}

Laboratory analysis that allows inclusion and exclusion criteria was performed in all patients and controls, however due to either non-compliance with the preanalytical phase or refusal of repeated blood sampling analysis for bone turnover markers and sRAGE was done only in a subset of 50 women with T2DM and 52 nondiabetic controls. Venous blood samples were taken after an overnight fast. Routine biochemical analyses were performed with fresh samples; other aliquots were stored at $-70^{\circ} \mathrm{C}$ before being analyzed. The serum glycated hemoglobin (HbAlc) concentrations were assessed by high performance liquid chromatography. The serum fasting glucose was measured by enzymatic colorimetric (GOD-PAP) method. Fasting serum sRAGE levels were measured by sandwich ELISA (enzyme-linked immunosorbent assay) using standard kits Quantikine, RD Systems, Minneapolis, USA, according to the manufacturer's protocol. The serum concentrations of serum intact parathyroid hormone (PTH) and total 25-hydroxyvitamin D (25-OHD) as well as bone turnover markers serum C-terminal telopeptide of collagen I $(\beta C T X)$, serum intact N-terminal propeptide of type I procollagen (PINP), and serum N-MID Osteocalcin were measured using the electrochemiluminescence-based immunoanalysis (Modular; Roche Diagnostics, Germany). The serum concentrations of tartrate-resistant acid phosphatase isoform 5b (TRAP 5b) was measured by using enzymoimmunoassay (BoneTRAP Assay, Immunodiagnostic Systems Limited, Boldon, UK).

\section{Statistical analysis}

All analyses were conducted using JMP $® 10.0 .0$ statistical software (Copyright (C) 2012 SAS Institute Inc.). Data were expressed by means and standard deviations if not otherwise stated. Differences between groups were calculated by Student's t-test. Correlation analyses were performed using Spearman's ranked correlation coefficient. To assess whether relationship with body composition indices or measured biochemical variables is specific for these parameters, adjustment for age and diabetes duration in subsequent analysis by multiple linear regression was done. All statistical tests were two-tailed and $\mathrm{p}<0.05$ was considered statistically significant.

\section{Results}

Study population

Table 1 shows the anthropometric characteristics 
and measured biochemical parameters of the postmenopausal women with and without T2DM. Women with T2DM did not differ from control subjects in age, weight or height; however body mass index (BMI) was slightly higher in T2DM women $(p=0.0497)$. The prevalence of obesity (defined by BMI $>30 \mathrm{~kg} / \mathrm{m}^{2}$ ) was $59 \%$ in T2DM postmenopausal women and $48 \%$ in control group.

Table 1. The anthropometric characteristics and measured biochemical variables of the postmenopausal women with and without T2DM.

\begin{tabular}{|c|c|c|c|}
\hline & $\begin{array}{c}\text { Postmenopausal } \\
\text { Women with T2DM }\end{array}$ & $\begin{array}{l}\text { Nondiabetic } \\
\text { controls }\end{array}$ & p value \\
\hline$N$ & 68 & 71 & \\
\hline Age (years) & $62.96 \pm 6.5$ & $63.23 \pm 8.8$ & ns \\
\hline YSM (years) & $13.36 \pm 7.5$ & $13.58 \pm 9.2$ & ns \\
\hline Weight (kg) & $86.04 \pm 20.7$ & $79.35 \pm 21.9$ & $\mathrm{~ns}$ \\
\hline Height (m) & $1.61 \pm 0.06$ & $1.61 \pm 0.07$ & ns \\
\hline$B M I\left(k g / m^{2}\right)$ & $33.21 \pm 8.2$ & $30.51 \pm 7.8$ & 0.049 \\
\hline$S-H b A_{l c}(\mathrm{mmol} / \mathrm{mol})$ & $52.57 \pm 14.3$ & $37.87 \pm 4$ & $<0.001$ \\
\hline S-glucose $(\mathrm{mmol} / \mathrm{l})$ & $7.1 \pm 2.0$ & $5.2 \pm 0.5$ & $<0.001$ \\
\hline Diabetes duration (years) & $7.36 \pm 6.9$ & - & - \\
\hline $\mathrm{S}-\mathrm{Ca}(\mathrm{mmol} / \mathrm{l})$ & $2.30 \pm 0.1$ & $2.27 \pm 0.1$ & ns \\
\hline S-Creatinine $(\mu \mathrm{mol} / \mathrm{l})$ & $67.5 \pm 11.8$ & $70.0 \pm 10.6$ & ns \\
\hline$e G F R\left(\mathrm{ml} / \mathrm{s} / 1.73 \mathrm{~m}^{2}\right)$ & $1.24 \pm 0.18$ & $1.19 \pm 0.16$ & ns \\
\hline $\mathrm{S}-25 \mathrm{OHD}(\mathrm{nmol} / \mathrm{l})$ & $52.0 \pm 25.0$ & $72.5 \pm 29.5$ & $<0.001$ \\
\hline S-intact PTH (pmol/l) & $5.2 \pm 2.5$ & $4.9 \pm 1.9$ & ns \\
\hline \multicolumn{4}{|l|}{ Bone markers } \\
\hline$N$ & 50 & 52 & \\
\hline$S-T R A P 5 b(I U / l)$ & $2.7 \pm 1.1$ & $2.6 \pm 1.1$ & ns \\
\hline$S-\beta C T X(n g / l)$ & $377.0 \pm 188.7$ & $408.0 \pm 158.1$ & ns \\
\hline$S-P I N P(\mu g / l)$ & $39.4 \pm 16.7$ & $45.5 \pm 17.3$ & 0.069 \\
\hline S-Osteocalcin $(\mu \mathrm{g} / \mathrm{l})$ & $17.9 \pm 6.7$ & $21.6 \pm 6.8$ & 0.015 \\
\hline$S-s R A G E(n g / l)$ & $1371.0 \pm 597.1$ & $1504.6 \pm 597.3$ & ns \\
\hline
\end{tabular}

Data are presented as mean values $( \pm S D)$. BMI: Body Mass Index, eGFR: estimated glomerular filtration rate; 25 OHD: 25-hydroxyvitamin D; intact PTH: intact parathyroid hormone; TRAP5b: tartrate-resistant acid phosphatase isoform 5b; $\beta C T X$ : C-terminal telopeptide of collagen type I; PINP: intact N-terminal propeptide of type I procollagen, sRAGE: soluble receptor for AGEs.

\section{Fat mass and lean mass indices}

The detailed differences in body composition indices of the two groups are presented in Table 2. We have found no significant difference in total fat mass indices FMI $\left(\mathrm{kg} / \mathrm{m}^{2}\right)$ and $\mathrm{FM} \%$ between T2DM and control subjects. However, a significantly different distribution of fat mass indices between T2DM women and control subjects was found. Diabetic women had significantly higher Trunk fat $\% \quad(52.3 \pm 5.3 \%$ vs. $46.3 \pm 6.1 \%, \mathrm{p}<0.001)$ and $\mathrm{A} / \mathrm{G}$ ratio $(1.05 \pm 0.13$ vs. $0.94 \pm 0.16 ; \mathrm{p}<0.001)$ as well as Trunk/legs $\mathrm{FM}$ ratio
$(1.75 \pm 0.50$ vs. $1.31 \pm 0.38 ; \mathrm{p}<0.001)$ versus control subjects. On the other hand, Legs FM\% was significantly lower in T2DM women $(31.34 \pm 5.3$ vs. $37.04 \pm 5.89$, $\mathrm{p}<0.001)$. When analyzing the lean mass indices, we have found no significant difference in total LM\% between T2DM patients versus control subjects; however, women with T2DM had slightly higher LMI versus control subjects $(p<0.05)$. Legs LMI was not significantly different between patients and control subjects; however, the Legs LM\% was significantly lower in T2DM patients versus controls $(31.32 \pm 2.0 \%$ vs. $32.34 \pm 1.7 \%$; $<<0.01)$. 
Table 2. Bone mineral density (BMD), percentages of low BMD and number of low-trauma fractures, and fat and lean mass distribution in postmenopausal women with and without T2DM.

\begin{tabular}{|c|c|c|c|}
\hline & $\begin{array}{c}\text { Postmenopausal } \\
\text { women with T2DM }\end{array}$ & Nondiabetic controls & p value \\
\hline$N$ & 68 & 71 & \\
\hline Age (years) & $62.96 \pm 6.5$ & $63.23 \pm 8.8$ & ns \\
\hline YSM (years) & $13.36 \pm 7.5$ & $13.58 \pm 9.2$ & ns \\
\hline Weight (kg) & $86.04 \pm 20.7$ & $79.35 \pm 21.9$ & ns \\
\hline Height $(m)$ & $1.61 \pm 0.06$ & $1.61 \pm 0.07$ & ns \\
\hline$B M I\left(\mathrm{~kg} / \mathrm{m}^{2}\right)$ & $33.21 \pm 8.2$ & $30.51 \pm 7.8$ & 0.049 \\
\hline BMD Lumbar Spine $\left(\mathrm{g} / \mathrm{cm}^{2}\right)$ & $0.96 \pm 0.16$ & $0.93 \pm 0.14$ & ns \\
\hline BMD Femoral neck $\left(\mathrm{g} / \mathrm{cm}^{2}\right)$ & $0.74 \pm 0.12$ & $0.74 \pm 0.11$ & $\mathrm{~ns}$ \\
\hline BMD Total Femur $\left(\mathrm{g} / \mathrm{cm}^{2}\right)$ & $0.94 \pm 0.14$ & $0.91 \pm 0.15$ & $\mathrm{~ns}$ \\
\hline BMD Distal Radius $\left(\mathrm{g} / \mathrm{cm}^{2}\right)$ & $0.63 \pm 0.07$ & $0.62 \pm 0.07$ & ns \\
\hline BMD Whole Body $\left(\mathrm{g} / \mathrm{cm}^{2}\right)$ & $1.07 \pm 0.12$ & $1.02 \pm 0.19$ & $\mathrm{~ns}$ \\
\hline Total Body Bone Mineral Content ( $g$ ) & $2115 \pm 348$ & $2087 \pm 326$ & $\mathrm{~ns}$ \\
\hline Normal (T-score $\geq-1.0)$ & $32.4 \%$ & $28.2 \%$ & $\mathrm{~ns}$ \\
\hline Osteopenia $($-score $<-1.0$ and $>-2.5)$ & $48.5 \%$ & $50.7 \%$ & ns \\
\hline Osteoporosis (T-score $\leq-2.5)$ & $19.1 \%$ & $21.1 \%$ & $\mathrm{~ns}$ \\
\hline Vertebral fractures (No. of patients) & $8(7)$ & $9(6)$ & - \\
\hline Non vertebral fractures (No. of patients) & $16(13)$ & $14(11)$ & - \\
\hline humerus & - & $1(1)$ & - \\
\hline forearm & $8(8)$ & $10(9)$ & - \\
\hline ankle/tibia & $8(5)$ & $3(2)$ & - \\
\hline \multicolumn{4}{|l|}{ Fat mass indices } \\
\hline$F M I\left(\mathrm{~kg} / \mathrm{m}^{2}\right)$ & $14.4 \pm 5.5$ & $13.35 \pm 5.2$ & ns \\
\hline$F M \%$ & $41.12 \pm 4.9$ & $41.19 \pm 5.97$ & ns \\
\hline A/G ratio & $1.05 \pm 0.13$ & $0.94 \pm 0.16$ & $<0.001$ \\
\hline Trunk fat\% & $52.3 \pm 5.27$ & $46.32 \pm 6.07$ & $<0.001$ \\
\hline Trunk/legs FM ratio & $1.75 \pm 0.50$ & $1.31 \pm 0.38$ & $<0.001$ \\
\hline Legs FMI $\left(\mathrm{kg} / \mathrm{m}^{2}\right)$ & $4.81 \pm 1.67$ & $4.46 \pm 1.70$ & ns \\
\hline Legs $F M \%$ & $31.34 \pm 5.3$ & $37.04 \pm 5.89$ & $<0.001$ \\
\hline \multicolumn{4}{|l|}{ Lean mass indices } \\
\hline$L M I\left(\mathrm{~kg} / \mathrm{m}^{2}\right)$ & $18.52 \pm 3.9$ & $17.18 \pm 2.9$ & $<0.05$ \\
\hline$L M \%$ & $57.22 \pm 4.7$ & $57.94 \pm 5.3$ & ns \\
\hline Legs LMI $\left(\mathrm{kg} / \mathrm{m}^{2}\right)$ & $6.07 \pm 1.5$ & $5.82 \pm 1.1$ & $\mathrm{~ns}$ \\
\hline Legs $L M \%$ & $31.32 \pm 2.0$ & $32.34 \pm 1.7$ & $<0.01$ \\
\hline
\end{tabular}

Data are presented as mean values $( \pm \mathrm{SD})$. FM: Fat mass; LM: Lean mass; FMI = Fat mass index; FM\%: percentage of total body Fat mass; Trunk fat \%: percentage of Trunk fat; Legs FM\%: percentage of Legs Fat mass; Trunk/Legs FM ratio: Trunk/Legs Fat mass ratio; A/G ratio: Android to gynoid FM ratio; LMI: Lean mass index; LM\%: percentage of total body Lean mass; Legs LM\%: percentage of Legs lean mass.

Bone mineral density, fractures and biochemical markers of bone turnover

In our cohort of 68postmenopausal women with T2DM, 32.4\% of women had normal BMD, $48.5 \%$ osteopenia and $19.1 \%$ osteoporosis, in control nondiabetic women $28.2 \%, 50.7 \%$ and $21.1 \%$ of subjects, resp. (Table 2). The prevalence of low-trauma vertebral and non-vertebral fractures in T2DM women was $11.8 \%$ and $23.5 \%$, resp. and $12.7 \%$ and $19.7 \%$, resp. in controls. We found no significant differences in measured BMD regions between T2DM women and nondiabetic controls (Table 2) and between fractured and non-fractured groups (Table 3 ). Circulating biochemical markers of bone formation, PINP and osteocalcin was lower in T2DM women, although only serum osteocalcin level reached a significant difference between T2DM and 
controls (the mean 17.9 $\pm 6.7 \mu \mathrm{g} / 1$ and $21.6 \pm 6.8 \mu \mathrm{g} / \mathrm{l}$, resp., $\mathrm{p}=0.015$ ) (Table 1). The concentrations of bone resorption markers serum $\beta C T X$ and TRAP5b as well as serum sRAGE were not significantly different between groups. T2DM postmenopausal women had significantly lower 25OHD levels when compared to controls (the mean $\quad 52.0 \pm 25.0$ vs. $\quad 72.5 \pm 29.5 \mathrm{nmol} / \mathrm{l} ; \quad \mathrm{p}<0.001)$ (Table 1).

Table 3. Comparison of anthropometric, bone mineral density, body composition and biochemical indices between postmenopausal women with T2DM and controls with (+) and without (-) low-trauma fractures.

\begin{tabular}{|c|c|c|c|c|}
\hline & \multicolumn{2}{|c|}{ T2DM } & \multicolumn{2}{|c|}{ Control } \\
\hline & Fracture (+) & Fracture (-) & Fracture (+) & Fracture (-) \\
\hline$N$ & 20 & 48 & 16 & 55 \\
\hline Age (years) & $65.1 \pm 6.2$ & $62.1 \pm 6.5$ & $65.0 \pm 7.7$ & $62.7 \pm 9.1$ \\
\hline YSM (years) & $13.9 \pm 6.9$ & $13.2 \pm 7.8$ & $17.3 \pm 8.4$ & $14.8 \pm 19.5$ \\
\hline$B M I\left(k g / m^{2}\right)$ & $32.7 \pm 6.1$ & $33.4 \pm 9.1$ & $29.8 \pm 5.7$ & $30.7 \pm 8.3$ \\
\hline \multicolumn{5}{|l|}{ Fat mass indices } \\
\hline$F M I\left(k g / m^{2}\right)$ & $14.68 \pm 4.13$ & $14.59 \pm 5.7$ & $12.98 \pm 3.8$ & $13.46 \pm 5.7$ \\
\hline$F M \%$ & $42.18 \pm 5.02$ & $40.65 \pm 4.87$ & $41.13 \pm 6.35$ & $41.39 \pm 4.6$ \\
\hline Trunk fat $\%$ & $53.47 \pm 5.43$ & $51.79 \pm 5.18$ & $46.93 \pm 4.7$ & $46.15 \pm 6.4$ \\
\hline Trunk/legs FM ratio & $1.85 \pm 0.56$ & $1.70 \pm 0.46$ & $1.30 \pm 0.30$ & $1.31 \pm 0.40$ \\
\hline$A / G$ ratio & $1.08 \pm 0.12$ & $1.03 \pm 0.13$ & $0.96 \pm 0.11$ & $0.94 \pm 0.17$ \\
\hline Legs FMI & $4.49 \pm 1.6$ & $4.56 \pm 1.7$ & $4.76 \pm 1.2$ & $4.83 \pm 1.8$ \\
\hline Legs $F M \%$ & $30.19 \pm 5.17$ & $31.84 \pm 5.27$ & $37.3 \pm 4.9$ & $36.9 \pm 6.2$ \\
\hline \multicolumn{5}{|l|}{ Lean mass indices } \\
\hline $\operatorname{LMI}\left(\mathrm{kg} / \mathrm{m}^{2}\right)$ & $18.4 \pm 2.6$ & $18.97 \pm 3.5$ & $16.83 \pm 2.7$ & $17.28 \pm 3.0$ \\
\hline$L M \%$ & $56.59 \pm 4.68$ & $57.48 \pm 4.75$ & $58.09 \pm 5.8$ & $57.4 \pm 3.7$ \\
\hline Legs LMI $\left(\mathrm{kg} / \mathrm{m}^{2}\right)$ & $5.89 \pm 1.0$ & $6.31 \pm 1,36$ & $5.59 \pm 0.9$ & $5.90 \pm 1.1$ \\
\hline Legs $L M \%$ & $30.58 \pm 1.98 *$ & $31.84 \pm 5.27$ & $32.52 \pm 1.6$ & $31.69 \pm 2.1$ \\
\hline \multicolumn{5}{|l|}{ Bone Mineral Density } \\
\hline Lumbar spine $\left(\mathrm{g} / \mathrm{cm}^{2}\right)$ & $0.957 \pm 0.173$ & $0.964 \pm 0.156$ & $0.911 \pm 0.124$ & $0.947 \pm 0.149$ \\
\hline Femoral neck $\left(\mathrm{g} / \mathrm{cm}^{2}\right)$ & $0.709 \pm 0.111$ & $0.754 \pm 0.126$ & $0.732 \pm 0.111$ & $0.746 \pm 0.121$ \\
\hline Total femur $\left(\mathrm{g} / \mathrm{cm}^{2}\right)$ & $0.901 \pm 0.142$ & $0.961 \pm 0.140$ & $0.875 \pm 0.112$ & $0.922 \pm 0.158$ \\
\hline Distal radius $\left(\mathrm{g} / \mathrm{cm}^{2}\right)$ & $0.619 \pm 0.082$ & $0.639 \pm 0.073$ & $0.615 \pm 0.077$ & $0.628 \pm 0.072$ \\
\hline Whole body $\left(\mathrm{g} / \mathrm{cm}^{2}\right)$ & $1.061 \pm 0.140$ & $1.076 \pm 0.118$ & $1.018 \pm 0.155$ & $1.043 \pm 0.082$ \\
\hline$S-H b A_{l c}(\mathrm{mmol} / \mathrm{mol})$ & $53.1 \pm 14.2$ & $51.4 \pm 13.8$ & $37.8 \pm 4.2$ & $37.9 \pm 4.0$ \\
\hline S-glucose (mmol/l) & $7.3 \pm 1.4$ & $7.0 \pm 2.2$ & $5.1 \pm 0.3$ & $5.2 \pm 0.6$ \\
\hline Diabetes duration (years) & $7.6 \pm 6.7$ & $7.3 \pm 7.0$ & - & - \\
\hline$e G F R\left(m l / s / 1.73 m^{2}\right)$ & $1.24 \pm 0.17$ & $1.24 \pm 0.18$ & $1.19 \pm 0.09$ & $1.21 \pm 0.17$ \\
\hline S-intact PTH (pmol/l) & $4.5 \pm 2.2$ & $5.7 \pm 2.6$ & $5.3 \pm 2.1$ & $4.7 \pm 1.8$ \\
\hline S-25OHD (nmol/l) & $63.75 \pm 21 *$ & $45.0 \pm 25$ & $77.5 \pm 32.75$ & $70.25 \pm 28$ \\
\hline \multicolumn{5}{|l|}{ Bone markers } \\
\hline$N$ & 20 & 30 & 16 & 36 \\
\hline S-TRAP5b (IU/l) & $2.4 \pm 1.2$ & $3.0 \pm 0.9$ & $2.7 \pm 1.1$ & $2.6 \pm 1.1$ \\
\hline$S-\beta C T X(n g / l)$ & $339.7 \pm 182.1$ & $391.7 \pm 195.2$ & $440.4 \pm 134.4$ & $391.8 \pm 168.5$ \\
\hline$S-P I N P(\mu g / l)$ & $37.5 \pm 15.4$ & $40.0 \pm 17.6$ & $50.9 \pm 18.0$ & $42.7 \pm 16.5$ \\
\hline S-Osteocalcin $(\mu \mathrm{g} / l)$ & $15.8 \pm 5.8$ & $18.5 \pm 6.7$ & $22.7 \pm 5.7$ & $21.0 \pm 7.3$ \\
\hline$S-s R A G E(n g / l)$ & $1313.1 \pm 511.9$ & $1402.4 \pm 643.4$ & $1525.1 \pm 463.2$ & $1496.4 \pm 650.2$ \\
\hline
\end{tabular}

t-test $* p<0.05$; Data are presented as mean values $( \pm S D)$. BMI: Body Mass Index, eGFR: estimated glomerular filtration rate; $250 H D$ : 25-hydroxyvitamin D; PTH: intact parathyroid hormone; TRAP5b: tartrate-resistant acid phosphatase isoform 5 b; $\beta C T X$ : C-terminal telopeptide of collagen I; PINP: intact N-terminal propeptide of type I procollagen, sRAGE: soluble receptor for AGEs; FM: Fat mass; FMI: Fat mass index; A/G ratio: Android to gynoid FM ratio; LM: Lean mass; LMI: Lean mass index. 
No noninvasive method for evaluating bone quality is clinically available at present; however, the presence of low trauma fractures could be used for the assessment of bone quality in individual patients. Next, we therefore compared body composition indices and biochemical variables between women with and without low trauma fractures (Table 3). Body height, body weight and BMI were not significantly different between women with and without fractures in both groups. As shown in Table 3, BMD at any site were also similar between women with and without fractures. As for body composition, legs LM\% was significantly lower in the T2DM group with fractures compared with those without it. Legs LMI, LM\% and fat mass indices were not significantly different between groups with and without fractures (Table 3). Bone markers were not significantly different between groups with and without fractures, although serum osteocalcin and serum TRAP $5 \mathrm{~b}$ tend to be lower in T2DM fracture group $(15.8 \pm 5.8 \mu \mathrm{g} / \mathrm{l}$ vs. $18.5 \pm 6.8$ and $2.4 \pm 1.2$ vs. $3.0 \pm 0.09$, osteocalcin and TRAP5b, resp.) (Table 3). Only 25OHD level was significantly higher in the T2DM group with fractures $(\mathrm{p}=0.008)$ (Table 3$)$.

\section{Correlation analysis}

Firstly, we investigated if indices of fat and muscle mass correlated with BMD. TF BMD was positively correlated with lean mass indices as well as with some fat mass indices both in T2DM and controls. The Spearman's ranked correlation coefficient in T2DM women were as follows: LMI (0.416, $\mathrm{p}=0.0005), \mathrm{LM} \%$ (0.327, $\mathrm{p}=0.0267)$, Legs LMI $(0.447, \mathrm{p}=0.0002)$ and Legs LM\% (0.287, $\mathrm{p}=0.0217)$ and FMI $(0.310, \mathrm{p}=0.0113)$ and Legs FMI $(0.271, \mathrm{p}=0.0280)$. To assess whether relationship with body composition indices or measured biochemical variables is specific for these parameters, adjustments for age and diabetes duration was done in subsequent analysis by multiple linear regression. The correlation between TF BMD and LMI, FMI and Legs LMI (Fig. 1) remained significant in T2DM $\left(\mathrm{r}^{2}=0.318\right.$, $\mathrm{p}=0.0408 ; \mathrm{r}^{2}=0.313, \mathrm{p}=0.0125$ and $\mathrm{r}^{2}=0.330, \mathrm{p}=0.0054$, resp. $)$ as well as in controls $\left(\mathrm{r}^{2}=0.206, \mathrm{p}=0.004 ; \mathrm{r}^{2}=0.181\right.$, $\mathrm{p}=0.0124$ and $\mathrm{r}^{2}=0.198, \mathrm{p}=0.0056$, resp.), whereas the relationship between Legs FMI and TF BMD was no longer significant in T2DM group (Fig. 1). Although, both LM and FM indices were significantly related to TF BMD, the total LMI and Legs LMI seems to be more closely related to TF BMD $(\mathrm{p}<0.001)$.
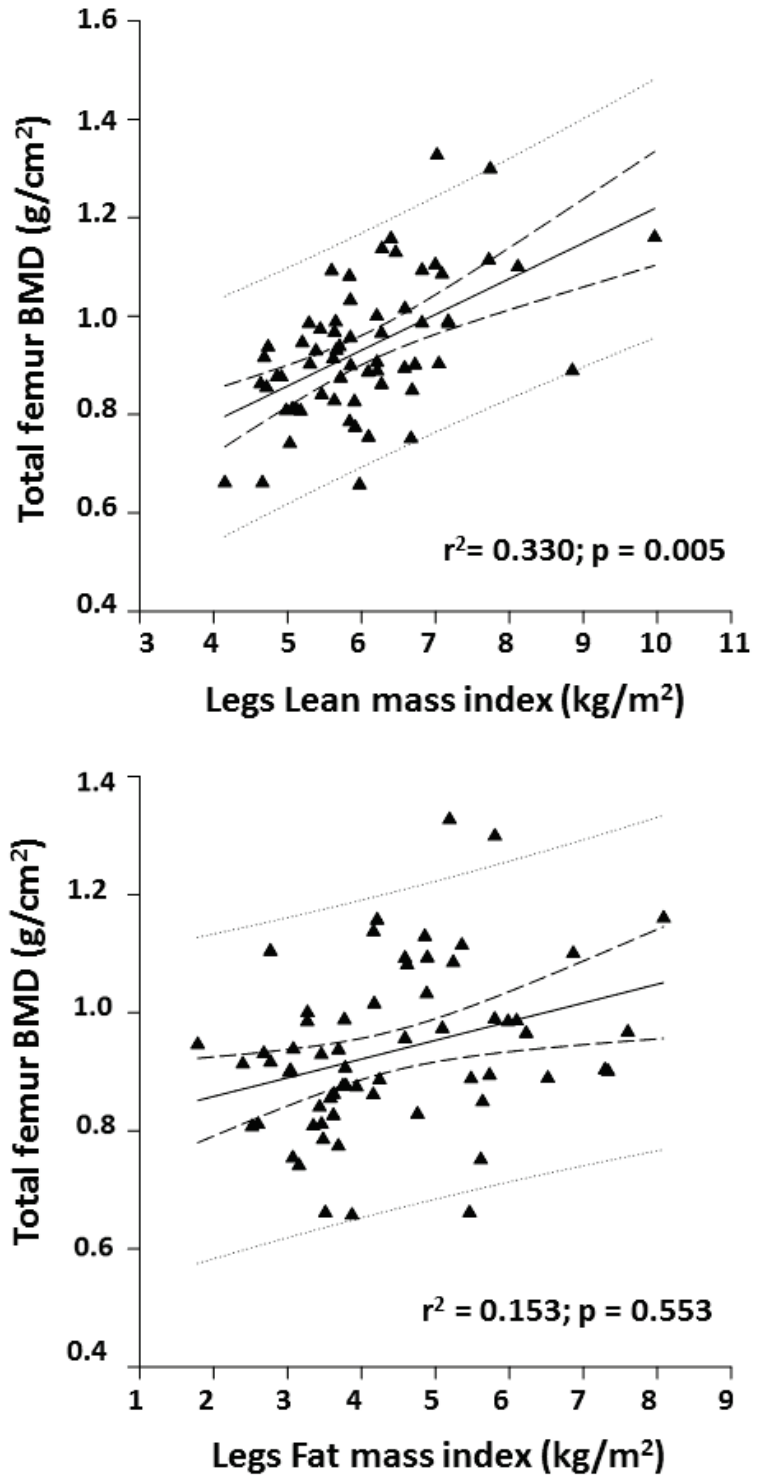

Fig. 1. Relationship between total femur bone mineral density (TF BMD; $\mathrm{g} / \mathrm{cm}^{2}$ ) and Legs Lean mass index $\left(\mathrm{kg} / \mathrm{m}^{2}\right.$; upper) or Legs Fat mass index $\left(\mathrm{kg} / \mathrm{m}^{2}\right.$; bottom) in postmenopausal women with T2DM. Dotted lines: prediction intervals. Multiple linear regression after adjustment for age and diabetes duration.

Secondly, we investigated if indices of fat and muscle mass correlated with measured biochemical parameters including $\mathrm{HbA}_{1 \mathrm{c}}$, glucose, and bone turnover markers, namely osteocalcin. Total LM\%, FM\% as well as Legs FMI negatively correlated with serum fasting glucose in control group after adjustment for age $\left(\mathrm{r}^{2}=0.386,0.422\right.$ and 0.334 , resp.). In T2DM women only Legs LM $\%$ negatively correlated with serum fasting glucose $\left(r^{2}=0.244, p=0.004\right)$ and with HbAlc $\left(r^{2}=0.244\right.$, $\mathrm{p}=0.009$ ) even after adjustments for age and diabetes duration. Serum osteocalcin in T2DM women negatively correlated with fat mass indices even after adjustments for age and diabetes duration: FMI $\left(\mathrm{r}^{2}=0.237, \mathrm{p}=0.0212\right)$, 
FM\% $\left(\mathrm{r}^{2}=0.255, \mathrm{p}=0.0120\right.$; Fig. 3$), \mathrm{A} / \mathrm{G}$ ratio $\left(\mathrm{r}^{2}=0.283\right.$, $\mathrm{p}=0.0053)$, Trunk fat $\%\left(\mathrm{r}^{2}=0.285, \mathrm{p}=0.0045\right.$; Fig. 2$)$, Trunk/fat legs fat mass $\left(\mathrm{r}^{2}=0.243, \mathrm{p}=0.0178\right)$ and positively correlated with Legs FM\% $\left(r^{2}=0.120 ; p=0.017\right)$ (Fig. 2) and total $\mathrm{LM} \%\left(\mathrm{r}^{2}=0.248, \mathrm{p}=0.0152\right)$ (Fig. 3). In the control group, our results showed similar associations
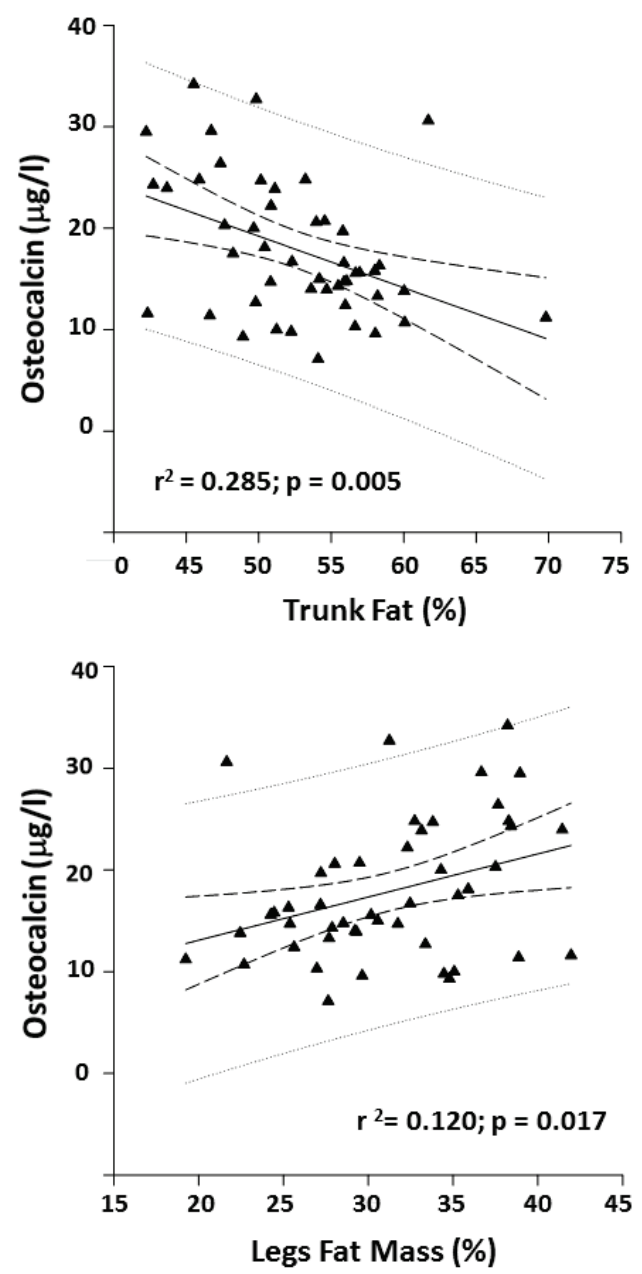

Fig. 2. Relationship between serum osteocalcin and Trunk Fat mass (\%; upper) or Legs Fat mass (\%; bottom) in postmenopausal women with T2DM. Dotted lines: prediction intervals. Multiple linear regression after adjustment for age and diabetes duration.

\section{Discussion}

Numbers of patients with osteoporosis or T2DM increase with age and both disorders adversely affect the health by causing fractures and vascular complications, respectively. Although osteoporosis and T2DM have been viewed as separate diseases, accumulating evidence indicates that similar pathophysiological mechanisms underlie both of them. The present study explored the impact of fat and muscle mass indices (measured by (data not shown). There were no significant associations of $25 \mathrm{OHD}$ concentrations with respect to serum calcium, intact PTH, creatinine or eGFR; however 25OHD was negatively associated with total FM in T2DM postmenopausal women $(\mathrm{r}=0.302 ; \mathrm{p}=0.031)$ as well as in controls $(\mathrm{r}=0.256, \mathrm{p}=0.044)$.
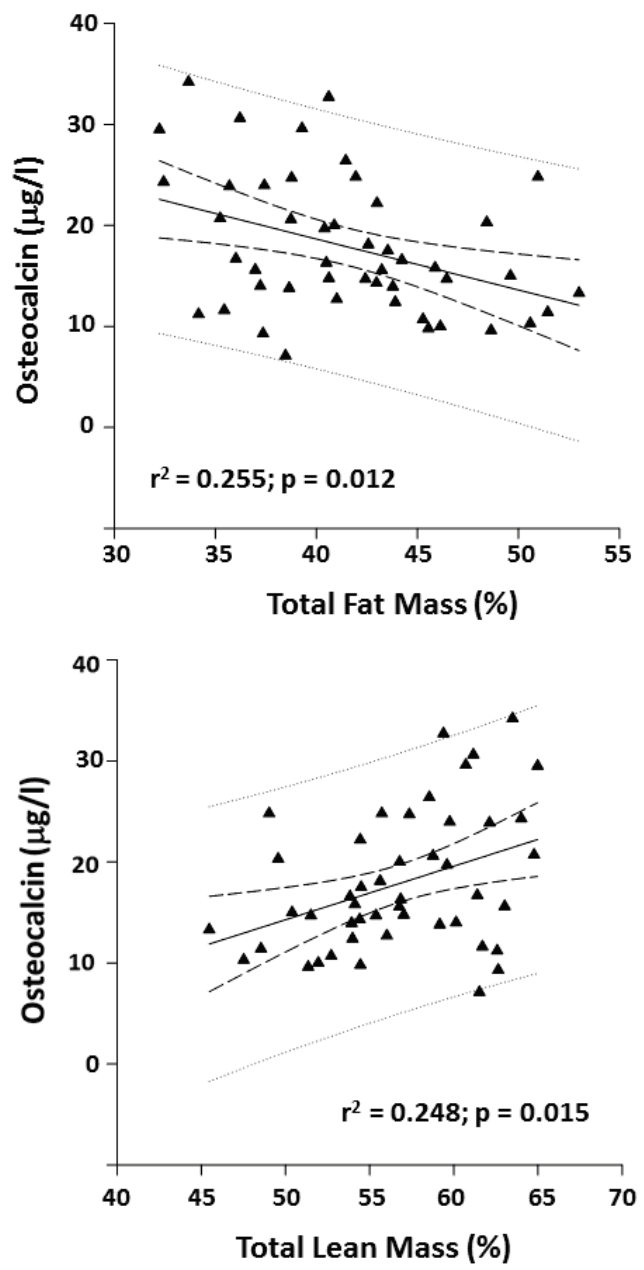

Fig. 3. Relationship between serum osteocalcin and Total Fat mass (\%; upper) or Total Lean mass (\%; bottom) in postmenopausal women with T2DM. Dotted lines: prediction intervals. Multiple linear regression after adjustment for age and diabetes duration.

DXA) on bone and glucose metabolism in postmenopausal women with and without T2DM.

Our results clearly showed significant differences in body composition between postmenopausal women with and without T2DM with its unfavorable distribution in T2DM women characterized by more central fat and decreased percentages of legs fat mass and legs lean mass. These results are in accordance with previous studies that have shown that patients with T2DM have central obesity as well as reduction of 
appendicular lean mass, particularly in the lower extremities, compared with subjects without it (Leenders et al. 2013, Moseley et al. 2011). We demonstrated that Legs LMI as well as total LMI or FMI significantly correlated with TF BMD both in T2DM women and controls even after adjusting for age and diabetes duration. As for body composition between fractured and non- fracture groups, only legs LM\% was significantly lower in the T2DM group with fractures compared with those without it (Table 3). These data suggest that lower muscle mass, especially in the lower limbs may be a risk factor for loss of hip BMD in postmenopausal women with T2DM, considering its future impacts on quality of life, physical disability and fracture risk in these patients.

There were no significant differences in total body BMC or BMD between the T2DM and the controls or between fractured and non-fracture groups. These results are in accordance with previous studies which demonstrated that BMD is generally higher in those with T2DM compared to those without (Vestergaard 2007). In contrast to normal or higher BMD in those with T2DM we documented a similar prevalence of low trauma fractures between postmenopausal women with and without T2DM (Table 2). However, it is well known that DXA technique has its own limitations. Further techniques, such as peripheral quantitative computed tomography which allows for separate assessment of the trabecular and cortical compartments of the bone, may provide better insight into the trabecular-cortical bone relationships (Sukumar et al. 2012); e.g. in a recent study, T2DM was associated with unfavorable cortical bone microarchitecture at the distal radius (Yu et al. 2015).

Previous studies have shown that low vitamin D, physical inactivity, hyperglycemia or AGEs are associated with muscle mass or muscle strength reduction (Tanaka et al. 2015). In the present study, the multivariate analysis confirms the negative correlation between Legs LM\% and serum HbAlc or fasting glucose in T2DM group. These results indicate that hyperglycemia might be a risk factor for loss of muscle mass in postmenopausal women with T2DM (Kalyani et al. 2014). More recently, Kalyani et al. reported that hyperglycemia measured by $\mathrm{HbA}_{1 \mathrm{c}}$ is associated with the lower muscle strength (Kalyani et al.2015). Reduced insulin signaling in T2DM leads to decreased protein synthesis and increased protein degradation, which can lead to reduced muscle mass. In addition, chronic inflammation, oxidative damage, and mitochondria dysfunction have also been suggested to be associated with both diabetes mellitus and reduced muscle quality (muscle strength/muscle mass). Among other risk factors, vitamin D deficiency may influence muscle quality.

In accordance with previous studies (Miñambres et al. 2015) we found a significantly higher prevalence of hypovitaminosis D (25OHD levels $<75 \mathrm{nmol} / \mathrm{l})$ in postmenopausal women with T2DM than in non-diabetic controls ( $82.4 \%$ vs. $54.2 \%$ ) (Table 1 ). Several studies have shown that obesity is associated with low serum 25OHD levels (Shantavasinkul et al. 2015). In our study, we found a significant negative association between $25 \mathrm{OH} \mathrm{D}$ levels and total body fat mass. This inverse 25OHD and fat mass relationship has been explained by "trapping" of the vitamin D parent compound, cholecalciferol, in adipose tissue. In the present study, the serum 25OHD levels are increased in T2DM patients with fracture compared to T2DM patients without fracture but they do not significantly differ from controls. We have no clear explanation for this result; however, direct measurement of sun exposure, seasonal variability as well as indoor or outdoor exercise patterns was not analyzed. Only three patients with fracture and five patients without fracture were using a low daily dose of cholecalciferol (500-1,000 IU).

In the present study, the positive correlation between BMD and total fat mass indices (FMI, FM\%) both in T2DM women and controls indicates that total fat mass is associated with BMD and may therefore protect against osteoporosis (de Laet et al. 2005); however, newer studies have demonstrated that abdominal obesity assessed by quantitative computed tomography, which can differentiate between visceral and subcutaneous adipose tissue, is inversely related to BMD (Bredella et al. 2011, Sheu et al. 2011). In our study, we demonstrated significantly higher trunk fat mass indices in T2DM women as compared with nondiabetic women (Table 1). There was no significant association between measured trunk fat indices and BMD and no significant differences in trunk fat mass indices between groups with and without fractures. No association between trunk fat mass and BMD in our study may be because most of women were overweight or obese and a higher fat mass distribution in soft tissue around the bone and within the marrow may affect DXA measurements (Hangartner et al. 1990). Previous DXA study in adolescent athletes found an inverse association between trunk fat mass and BMD (Ackerman et al. 2011). More importantly, recent bone biopsy study by Cohen et al. (2013) demonstrated that higher trunk fat mass is associated with inferior bone 
quality, namely with markedly lower static and dynamic parameters of bone formation and with thinner trabeculae and higher cortical porosity (Cohen et al. 2013). These results suggest that abdominal obesity may have an important influence on bone remodeling and bone quality, which may occur independently on BMD.

We found that serum bone formation marker osteocalcin was significantly lower in T2DM postmenopausal women (Table 1). The marker of bone collagen synthesis serum PINP and bone resorption markers, serum $\beta C T X$ and TRAP5b, were also lower (although differences did not reach statistical significance), suggesting a decrease in bone remodeling. Several other studies have evaluated the relationships between obesity and serum bone formation markers in premenopausal and postmenopausal women and found that bone turnover markers, such as osteocalcin were lower in obese than normal-weight subjects (Bredella et al. 2011, Lee et al. 2012, Garcia-Martin et al. 2011). Moreover, in our study serum osteocalcin was inversely associated with total $\mathrm{FM} \%$ and trunk fat mass indices (Trunk FM\%, A/G ratio and Trunk/legs FM ratio) in postmenopausal women with and without T2DM even after adjustments for age and diabetes duration (Fig. 2, 3). In contrast, accumulation of fat in the legs (Legs FM\%) positively associated with osteocalcin levels (Fig. 2). In addition, there was a significant positive correlation between serum osteocalcin and total LM\% (Fig. 3). Although, the mechanism(s) by which fat mass, particularly central fat mass affects the bone remodeling is unknown (Cohen et al. 2013), studies in animal models strongly support the view that osteocalcin may play an important role in fat-bone relationships (Lee et al. 2014). On the other hand, adipose tissue is also considered as endocrine organ, which may produce osteocalcin (Foresta et al. 2010). There was a strong positive correlation between osteocalcin and PINP or measured bone resorption markers (data not shown), which suggests coupling between bone formation and bone resorption; however, our results found that only circulating osteocalcin, but not PINP, $\beta C$ TX or TRAP5b, were associated with fat mass indices. These findings suggest that mature osteoblast or osteocytes function is specifically affected by glucose metabolism in postmenopausal women.

The concentrations of serum sRAGE were not significantly different between T2DM and control group or between patients with and without fracture. At present, it is unclear whether circulating sRAGE is elevated in all patients with $\mathrm{T} 2 \mathrm{DM}$ - as higher, lower, and even similar levels of sRAGE have been reported in patients with T2DM compared with control nondiabetic subjects (Yamagishi and Matsui 2010). These contradictory findings may be at least partly explained by differences in the renal function in diabetic patients in these studies. In our study, there were no signs of renal complications in T2DM patients or controls at the time of examination, which could at least partly explain no differences in sRAGE between groups.

\section{Limitations}

The present study was observational, and provides limited insight to unravel underlying pathophysiological mechanisms of the observed relationships. We studied only subjects who visited our hospital, a tertiary center, for evaluation and treatment diabetes mellitus and osteoporosis. Therefore, the subjects enrolled in the present study might not be representative of Czech postmenopausal women with the disorders. Measuring body composition by dual energy X-ray absorptiometry (DXA) is a noninvasive and valid method that allows separation of the body mass into bone mass, fat mass, and lean (fat free) mass; however, this technique has its own limitations. Although, trunk fat measured by DXA is considered a surrogate for visceral fat mass, it cannot differentiate between visceral and subcutaneous adipose tissue and includes fat in the rib and pelvis compartments. In fact, the variable fat mass distribution in soft tissues in obese women may have interfered with our ability to detect differences with the 2-dimensional DXA assessment.

\section{Conclusions}

In contrast to normal or higher BMD in those with T2DM, we documented a similar prevalence of low trauma fractures between postmenopausal women with and without T2DM. These findings suggest that poor bone quality rather than decreased bone mass may define bone fragility that causes low trauma fractures in T2DM. In postmenopausal women with T2DM, lower muscle mass (total LM\%) and higher trunk fat mass was accompanied by significantly lower serum osteocalcin levels, a specific marker of osteoblast and osteocytes activity. These results suggest that abdominal obesity and lower muscle mass might be related to low bone formation in T2DM women. Moreover, in our study, legs muscle mass (Legs LM\%) was significantly lower in 
fractured T2DM women as compared with non-fractured patients. The hyperglycemia contributes to decline in muscle mass, especially in the lower extremities, which may further contribute to poor bone quality in T2DM women. Further research is needed to unravel underlying pathophysiological mechanisms and to determine whether maintenance of muscle mass and/or reduction of central fat mass can prevent fractures and improve the glucose metabolism in T2DM postmenopausal women.

\section{Conflict of Interest}

There is no conflict of interest.

\section{Acknowledgements}

The authors thank Věra Lánská RNDr, CSc. for the excellent statistical support, Mrs. Oldřiška Lukášková, Mrs. Jana Křenková and Mrs. Markéta Urbánková for the technical assistance. This work was supported by IGA Ministry of Health of Czech Republic No. NT 11335$6 / 2010$.

\section{References}

ACKERMAN KE, DAVIS B, JACOBY L, MISRA M: DXA surrogates for visceral fat are inversely associated with bone density measures in adolescent athletes with menstrual dysfunction. J Pediatr Endocrinol Metab 24: 497-504, 2011.

BREDELLA MA, TORRIANI M, GHOMI RH, THOMAS BJ, BRICK DJ, GERWECK AV, HARRINGTON LM, BREGGIA A, ROSEN CJ, MILLER KK: Determinants of bone mineral density in obese premenopausal women. Bone 48: 748-754, 2011.

CAFFARELLI C, ALESSI C, NUTI R, GONNELLI S: Divergent effects of obesity on fragility fractures. Clin Interv Aging 9: 1629-1636, 2014.

COHEN A, DEMPSTER DW, RECKER RR, LAPPE JM, ZHOU H, ZWAHLEN A, MÜLLER R, ZHAO B, GUO X, LANG T, SAEED I, LIU XS, GUO XE, CREMERS S, ROSEN CJ, STEIN EM, NICKOLAS TL, MCMAHON DJ, YOUNG P, SHANE E: Abdominal fat is associated with lower bone formation and inferior bone quality in healthy premenopausal women: a transiliac bone biopsy study. J Clin Endocrinol Metab 98: 2562-2572, 2013.

DE LAET C, KANIS JA, ODÉN A, JOHANSON H, JOHNELL O, DELMAS P, EISMAN JA, KROGER H, FUJIWARA S, GARNERO P, MCCLOSKEY EV, MELLSTROM D, MELTON LJ 3RD, MEUNIER PJ, POLS HA, REEVE J, SILMAN A, TENENHOUSE A: Body mass index as a predictor of fracture risk: a metaanalysis. Osteoporos Int 16: 1330-1338, 2005.

FORESTA C, STRAPAZZON G, DE TONI L, GIANESELLO L, CALCAGNO A, PILON C, PLEBANI M, VETTOR R: Evidence for osteocalcin production by adipose tissue and its role in human metabolism. J Clin Endocrinol Metab 95: 3502-3506, 2010.

GARCIA-MARTIN A, CORTES-BERDONCES M, LUQUE-FERNANDEZ I, ROZAS-MORENO P, QUESADACHARNECO M, MUNOZ-TORRES M: Osteocalcin as a marker of metabolic risk in healthy postmenopausal women. Menopause 18: 537-541, 2011.

HANGARTNER TN, JOHNSTON CC: Influence of fat on bone measurements with dual energy absorptiometry. Bone Miner 9: 71-81, 1990.

KALYANI RR, CORRIERE M, FERRUCCI L: Age-related and disease-related muscle loss: the effect of diabetes, obesity, and other diseases. Lancet Diabetes Endocrinol 2: 819-829, 2014.

KALYANI RR, METTER EJ, EGAN J, GOLDEN SH, FERRUCCI L: Hyperglycemia predicts persistently lower muscle strength with aging. Diabetes Care 38: 82-90, 2015.

KANAZAWA I: Osteocalcin as a hormone regulating glucose metabolism. World J Diabetes 6: 1345-1354, 2015.

KANIS JA, GLÜER CC: An update on the diagnosis and assessment of osteoporosis with densitometry. Committee of Scientific Advisors, International Osteoporosis Foundation. Osteoporos Int 11: 192-202, 2000.

LEE SW, JO HH, KIM MR, YOU YO, KIM JH: Association between obesity, metabolic risks and serum osteocalcin level in postmenopausal women. Gynecol Endocrinol 28: 472-477, 2012. 
LEE CG, BOYKO EJ, BARRETT-CONNOR E, MILJKOVIC I, HOFFMAN AR, EVERSON-ROSE SA, LEWIS CE, CAWTHON PM, STROTMEYER ES, ORWOLL ES: Osteoporotic Fractures in Men (MrOS) Study Research Group. Insulin sensitizers may attenuate lean mass loss in older men with diabetes. Diabetes Care 34: 2381-2386, 2011.

LEE NK, SOWA H, HINOI E, FERRON M, AHN JD, CONFAVREUX C, DACQUIN R, MEE PJ, MCKEE MD, JUNG DY, ZHANG Z, KIM JK, MAUVAIS-JARVIS F, DUCY P, FERRON M, LACOMBE J: Regulation of energy metabolism by the skeleton: osteocalcin and beyond. Arch Biochem Biophys 561: 137-146, 2014.

LEENDERS M, VERDIJK LB, VAN DER HOEVEN L, ADAM JJ, VAN KRANENBURG J, NILWIK R, VAN LOON LJ: Patients with type 2 diabetes show a greater decline in muscle mass, muscle strength, and functional capacity with aging. J Am Med Dir Assoc 14: 585-592, 2013.

LOHMAN M, TALLROTH K, KETTUNEN JA, MARTTINEN MT: Reproducibility of dual-energy x-ray absorptiometry total and regional body composition measurements using different scanning positions and definitions of regions. Metab Clin Exp 58: 1663-1668, 2009.

MARTINEZ-LAGUNA D, TEBE C, JAVAID MK, NOGUES X, ARDEN NK, COOPER C, DIEZ-PEREZ A, PRIETO-ALHAMBRA D: Incident type 2 diabetes and hip fracture risk: a population-based matched cohort study. Osteoporos Int 26: 827-833, 2015.

MIÑAMBRES I, SÁNCHEZ-QUESADA JL, VINAGRE I, SÁNCHEZ-HERNÁNDEZ J, URGELL E, DE LEIVA A, PÉREZ A: Hypovitaminosis D in type 2 diabetes: relation with features of the metabolic syndrome and glycemic control. Endocr Res 40: 160-165, 2015.

MOSELEY KF, DOBROSIELSKI DA, STEWART KJ, DE BEUR SM, SELLMEYER DE: Lean mass and fat mass predict bone mineral density in middle-aged individuals with noninsulin-requiring type 2 diabetes mellitus. Clin Endocrinol (Oxf) 74: 565-571, 2011.

SHANTAVASINKUL PC, PHANACHET P, PUCHAIWATTANANON O, CHAILURKIT LO, LEPANANON T, CHANPRASERTYOTIN S, ONGPHIPHADHANAKUL B, WARODOMWICHIT D: Vitamin D status is a determinant of skeletal muscle mass in obesity according to body fat percentage. Nutrition 31: 801-806, 2015.

NG AC, MELTON LJ 3RD, ATKINSON EJ, ACHENBACH SJ, HOLETS MF, PETERSON JM, KHOSLA S, DRAKE MT: Relationship of adiposity to bone volumetric density and microstructure in men and women across the adult lifespan. Bone 55: 119-125, 2013.

PARK SW, GOODPASTER BH, LEE JS, KULLER LH, BOUDREAU R, DE REKENEIRE N, HARRIS TB, KRITCHEVSKY S, TYLAVSKY FA, NEVITT M, CHO YW, NEWMAN AB: Health, Aging, and Body Composition Study. Excessive loss of skeletal muscle mass in older adults with type 2 diabetes. Diabetes Care 32: 1993-1997, 2009.

SHEU Y, CAULEY JA: The role of bone marrow and visceral fat on bone metabolism. Curr Osteoporos Rep 9: 67-75, 2011.

STARUP-LINDE J, VESTERGAARD P: Management of endocrine disease: Diabetes and osteoporosis: cause for concern? Eur J Endocrinol 173: R93-R99, 2015.

SUKUMAR D, SCHLUSSEL Y, RIEDT CS, GORDON C, STAHL T, SHAPSES SA: Obesity alters cortical and trabecular bone density and geometry in women. Osteoporos Int 22: 635-645, 2011.

TANAKA K, KANAZAWA I, SUGIMOTO T: Elevated serum pentosidine and decreased serum IGF-I levels are associated with loss of muscle mass in postmenopausal women with type 2 diabetes mellitus. Exp Clin Endocrinol Diabetes 124: 163-166, 2016.

VESTERGAARD P: Discrepancies in bone mineral density and fracture risk in patients with type 1 and type 2 diabetes--a meta-analysis. Osteoporos Int 18: 427-444, 2007.

YAMAGISHI SI, MATSUI T: Soluble form of a receptor for advanced glycation end products (sRAGE) as a biomarker. Front Biosci (Elite Ed) 2: 1184-1195, 2010.

YAMAMOTO M, YAMAGUCHI T, YAMAUCHI M, KAJI H, SUGIMOTO T: Diabetic patients have an increased risk of vertebral fractures independent of BMD or diabetic complications. J Bone Miner Res 24: 702-709, 2009. 
YU EW, PUTMAN MS, DERRICO N, ABRISHAMANIAN-GARCIA G, FINKELSTEIN JS, BOUXSEIN ML: Defects in cortical microarchitecture among African-American women with type 2 diabetes. Osteoporos Int 26: 673-679, 2015. 